\title{
PESAN DAKWAH ISLAM DALAM NYANYIAN RAKYAT \\ (Pemaknaan atas Teks-Teks Kabhanti Kantola pada Masyarakat Muna)
}

\author{
Hardin \\ Universitas Halu Oleo Kendari, Indonesia \\ hardinatty@gmail.com \\ Hadirman \\ Intitut Agama Islam Negeri Manado, Indonesia \\ hadirman@iain-manado.ac.id
}

\begin{abstract}
Abstrak. Nyanyian rakyat merupakan salah satu unsur budaya yang universal. Nyanyian rakyat sebagai bagian dalam budaya lokal selain bersifat menghibur dan mendidik, dapat dijadikan pula sebagai media dakwah Islam. Salah satu nyanyian rakyat yang digunakan masyarakat Muna dalam menyisipkan pesan dakwah Islam adalah kabhanti kantola. Pesan dakwah Islam disisipkan pemantun dalam teks-teks kabhanti kantola yang diciptakannya. Masyarakat yang menyaksikan dan mendengar teks-teks kabhanti kantola tersebut dapat mengetahui pesan-pesan dakwah Islam yang terkandung di dalamnya. Penelitian ini bertujuan mendeskripsikan bentuk-bentuk pesan dakwah Islam yang terkandung teks-teks kabhanti kantola pada masyarakat Muna. Hasil penelitian menunjukkan bahwa kabhanti kantola pada masyarakat Muna dijadikan sebagai salah satu media dakwah Islam. Pesan dakwah Islam dihadirkan dan diproduksi oleh pemantun berupa teks-teks yang mengandung nilai-nilai ajaran Islam. Pesan dakwah Islam yang disisipkan dalam teks-teks kabhanti kantola terdiri atas: (1) pesan menguatkan keimanan kepada Allah, (2) pesan mensyukuri nikmat Allah, (3) pesan menjauhi barang haram, (4) pesan menghargai sesama manusia, (5) pesan memohon maaf.
\end{abstract}

Kata kunci: Pesan Dakwah Islam, Nyanyian rakyat, Teks-teks kabhanti kantola, dan Masyarakat Muna.

Abstract. Folksong is one of universal elements of a culture. Folksongs, as a part of the local culture, not only entertain and educate but also become a medium for Islamic da'wah. One of folksongs used by the Muna peopleto deliver Islamic da'wah messages is Kabhanti Kantola. The messages in this folksong are inserted through stanzas. People who watch and listen to Kabhanti Kantola acknowledge and understand the da'wah contained. This research aims to describe and interprete the forms of Islamic da'wah messages contained 
in Kabhanti Kantola in Muna People. The research findings shows that Kabhanti Kantola in Muna people is used as one of Islamic da'wah media. The messages that composed and sung by the singers reflect Islamic teachings. Among Islamic da'wah messages which are inserted in the texts are 1) message to strengthen faith toward Allah 2) message to be grateful for the blessings of Allah 3) message to avoid forbidden objects 4) message to respect other people 5) message to ask for forgiveness.

Key words: Islamic Da'wah messages, folksong, Kabhanti Kantola text, Muna People

\section{A. Pendahuluan}

Masyarakat Muna merupakan salah satu etnik yang hidup dan menetap di Pulau Muna Provinsi Sulawesi Tenggara dan beberapa daerah lain di Indonesia, seperti di Kota Kendari, di Kota Makassar, di Kota Gorontalo, di Kota Bitung, di Kota Manado. Masyarakat Muna yang menetap di Pulau Muna memiliki seni pertunjukan yang dikenal dengan nama nyanyian rakyat kabhanti. Kabhanti yang dimiliki masyarakat Muna terdiri atas empat bentuk, yakni kabhanti kantola, kabhanti gambusu, kabhanti modero, dan kabhanti watulea. Salah satu jenis kabhanti yang dikaji dalam artikel ini adalah kabhanti kantola dilihat sebagai media dakwah.

Pertunjukan kabhanti kantola pada masa lalu dilakukan semalam suntuk. Pertunjukannya biasanya dilakukan setelah isya sampai subuh. Pada saat pertunjukan kabhanti kantola pemantu laki-laki dan perempuan saling berbalas pantun. Para pemantun saling berhadaphadapan antara salah kelompok pemantun dengan kelompok lain yang menjadi lawan mainnya. Penonton biasanya ada yang berdiri dan duduk, serta mengelilingi tempat pementasan sambil memberikan respons suasana pertunjukkan, baik melalui bahasa lisan maupun bahasa tubuh (gesture).

Nyanyian rakyat ini sebagai bagian dari alat komunikai tradisional yang cukup efektif untuk mengkomunikasi segala aspek kehidupannya. Nyanyian rakyat ini dapat mempengaruhi pengalaman, pikiran, dan emosi orang yang menyaksikannya. Bahkan dalam pertunjukannya, masih fungsional pada masyarakat pendukungnya. Pesan-pesan yang tercermin dalam teks-teks nyanyian rakyat tersebut mudah diterima dan menghibur bagi siapa saja yang menyaksikannya. Pesan-pesan yang dihadirkan pemantun dalam nyanyian rakyat kabhanti kantola tidak hanya berkaitan dengan sosioreligius, tetapi juga pesan-pesan moral, percintaan, kerinduan, dan sebagainya.

Penyampaian pesan dalam pertunjukkan kabhanti kantola dilakukan secara informatif dan ekspresif oleh pemantunnya, sehingga secara langsung pula memberikan informasi dan mempengeruhi pikiran dan perasaan orang lain yang mendengarnya. Dengan demikian, dapat dikatakan bahwa kabhanti kantola menjadi salah satu instrumen untuk menyampaikan pengalaman, pikiran, perasaan (emosi) ${ }^{1}$. Teks kabhanti kantola yang diciptakan pemantun dan diperdengarkan kepada pemantun lain dan penonton menjadi sarana tersebar luasnya pengalaman, pikiran dan perasaan (emosi), termasuk keyakinan dan nilai-nilai positif, serta prasangka tertentu. Jadi, teks kabhanti kantola yang diciptakan pemantun bukanlah suatu bentuk kata-kata indah semata, tetapi meng-

Deddy Mulyana. Ilmu Komunikasi Suatu Pengantar, (Bandung: Remaja Rosdakarya, 2009), h. 24. 
gambarkan nilai-nilai kehidupan manusia yang universal. Nilai-nilai kehidupan tersebut, dapat dirasakan sendiri oleh pemantun dan pemantun lain serta penonton yang menyaksikan pertunjukan kabhanti kantola.

Hal ini mengindikasikan bahwa melalui nyanyian rakyat kabhanti kantola masyarakat dapat memperoleh saluran untuk mengekspresikan pengalaman, pikiraan, perasaan (emosi) untuk mengasah kepekaan batinnya. Sumber daya bahasa verbal dalam teks-teks kabhanti kantola tersebut sebagai suatu cerminan pengalaman, pikiran, dan perasaan ditransmisikan pula untuk orang lain, sehingga bagi yang menyaksikannya akan memperolah pesan untuk mencerahkan jiwanya.

Nyanyian rakyat ini dapat dijadikan sebagai media untuk menyampaikan pesan-pesan dakwah yang mudah diterima oleh khalayak. Sifatnya yang menghibur dapat dimanfaatkan pemantun untuk menyisipkan pesan-pesan dakwah di dalam teks kabhanti kantola yang diciptakannya. Karena sifatnya tontonan (hiburan) dan tuntunan (hidup), maka penikmatnya pun tidak akan bosan mendengarnya meskipun konstruksi teks itu mengalami perulangan bentuk (formula). Bahkan, bentuk-bentuk teks itu akan mudah ditiru oleh pendengarnya karena menarik dan terungkap dalam bahasa yang mudah dipahami. Meskipun, terdapat pula bentuk-bentuk kiasan, tetapi karena diungkapkan dalam bahasa daerah pemiliknya, tidak menjadi kendala untuk memahami pesan yang terkandung dalam teks itu.

Nyanyian rakyat kabhanti kantola dewasa ini kian terabaikan. Hal ini tidak terlepas dengan kondisi zaman yang semakin berkembang dan daya sebar kebudayaan popular yang bukan hanya berkembang di perkotaan, tetapi juga telah merambah ke pedesaan. Fonomena ini, sebagai sebuah imbas dari kapitalisme global yang dikhawatirkan semua pihak. Budaya lokal yang sarat dengan nilai-nilai moral kalah bersaing dengan kebudayaan popular. Dampaknya adalah "budaya dan pola-pola tradisi masyarakat (lokal) mengalami kepunahan disebabkan oleh hantaman palu pembangunan yang dilancarkan dengan semangat kapitalisme yang tanpa moral. ${ }^{2}$ Potensi nyanyian rakyat kabhanti kantola sebagai media dakwah dan pembentuk kepribadian ini, akan semakin ditinggalkan generasi penerusnya. Jika tidak diwariskan pada generasi ahli waris, maka generasi muda akan meninggalkannya. Jika hal ini terjadi demikian, maka kepunahan nyanyian rakyat ini tak terelakan.

Berdasarkan pemikiran di atas penulis tertarik untuk menggali teks-teks nyanyian rakyat kabhanti kantola khususnya yang mencerminkan pesan-pesan dakwah Islam. Pesan dakwah yang dimaksud adalah bentuk kata atau kalimat teks-teks kabhanti kantola pada masyarakat Muna, yang mengandung ajaran Islam (selaras dengan al-Quran dan alhadis) atau yang berkaitan ajaran nilai-nilai Islam. Permasalahan yang dikaji dalam artikel ini adalah bagaimanakah bentuk-bentuk pesanpesan dakwah Islam dalam teks-teks kabhanti kantola pada masyarakat Muna? Tujuan penulisan artikel ini adalah adalah untuk mendeksripsikan dan menginterpretasi bentuk pesan-pesan dakwah Islam dalam teks-teks kabhanti kantola pada masyarakat Muna.

\section{B. Pembahasan}

\section{Hakikat Kabhanti pada Masyarakat Muna}

Secara etimologis bahasa, bahwa secara etimologis kabhanti merupakan kata jadian yang terdiri atas morfem $k a$ - dan kata dasar

Nasution. H. Pandapotan. Adat Budaya Mandailing dalam Tantangan Zaman, (Medan: Forkala, 2005). 
bhanti. Morfem terikat $k a$ - berfungsi sebagai pembentuk kata benda, sedangkan morfem bhanti mengandung pengertian puisi. ${ }^{3}$ Defenisi yang lain, kabhanti dikonsepsikan sebagai puisi, saja, atau nyanyian. ${ }^{4}$ Kabhanti, selain terdapat di Muna, juga dikenal oleh masyarakat Buton. baik yang berkembang di Keraton Buton maupun di luar Keraton Buton. Kabhanti yang terdapat di Keraton Buton ini umumnya ditulis dan diciptakan oleh pewarisan keraton (para sultan). Kabhanti yang berkembang di dalam keraton umumnya berisi tuntunan dan falsafah yang bersumber dari ajaran Islam. Kabhanti yang berkembang di luar Keraton Buton diciptakan oleh masyarakat luas, umumnya berisi ungkapan perasaan, cinta-kasih, kesedihan, kebahagian, maupun kerinduan. ${ }^{5}$

Kembali pada pembahasan kabhanti Muna bahwa tidak hanya berbeda tempat (letak geografis), aspek penciptaan, isi, acara (teknik pendokumentasian), dan ciri khas kebudayaan pendukungnya dengan kabhanti Buton, tetapi juga dari aspek pertunjukannya. Bahkan bentuk-bentuk kabhanti yang berkembang pada masyarakat Muna sangat beragam ${ }^{6}$, seperti diuraikan sebagai berikut.

1) Kabhanti kantola, yaitu kabhanti yang digunakan pada waktu bermain kantola. Kantola adalah sejenis permainan tradisional, di mana para pemain berdiri berhadapan antara pemain laki-laki dan perempuan. Mereka berbalas pantun dengan irama lagu ruuruunte atau ruuruuntete. Irama ruuruunte ini menggunakan paling tinggi

La Niampe. "Kabhanti Bula Malino: Kajian Filologi Sastra Wolio Klasik", Tesis, (Bandung: Program Pascasarjana Universitas Padjadjaran, 1998), h. 54.

4 Anceaux, J.C.The Wolio Language: Outline of Grammatical Deskription and Texts. (Holand: Foris Publications, 1998), h.51.

5 Asrif. "Sastra Kabanti: Pengertian, Jenis, dan Fungsi" dalam Kandai Jurnal Bahasa dan Sastra Volume 6, Nomor 2 November 2010, (Kendari: Kantor Bahasa Provinsi Sulawesi Tenggara, 2010).

6 La Mokui. Kabhanti Wuna (Pantun Muna), (Raha: CV Astri Raha, 1994), h. 6-8. lima nada. Acara kantola biasanya dilaksanakan malam hari setelah selesai panen ubi kayu dan ubi jalar. Adapun bentuk syair kabhanti kantola, sepintas lalu dapat dikatakan prosa liris, yakni prosa yang mementingkan irama. Akan tetapi bila kita teliti benar sebagian dapat digolongkan bentuk pantun yang disebut talibun, yakni pantun yang lebih dari empat baris tetapi genap jumlahnya.

2) Kabhanti Watulea adalah kabhanti yang menggunakan irama Watulea. Kabhanti macam ini biasanya dinyanyikan pada waktu menebas hutan atau berkebun. Sambil bekerja mereka menyanyi bersamasama atau sendirian. Kadang-kadang dinyanyikan agar tidak kesepian di tempat kesunyian. Syair kabhanti Watulea sebenarnya hanya dua baris dan masing-masing baris terdiri atas tiga kata atau dua kata lebih bila kata itu agak panjang. Bentuknya hampir sama dengan pantun kilat atau karmina, contoh: Koe ghondo kakesano/ ghondo torano mingkuno 'Jangan lihat kecantikannya/lihatlah perangainya'.

3) Kabhanti gambusu, yakni pantun yang dinyanyikan dengan diiringi oleh irama gambus. Kadang-kadang instrumen yang digunakan tidak hanya gambus, tetapi dilengkapi dengan biola, kecapi, serta botol kosong yang ditabuh atau dipukul dengan sendok atau paku mengikuti irama lagu dan bunyi-bunyi instrumen enak didengar.

4) Kabhanti modero; sebenarnya sama dengan kabhanti gambusu. Kabhanti gambusu sering pula dinyanyikan pada waktu bermain modero. Oleh sebab itu, kabhanti gambusu disebut pula kabhanti modero. Modero adalah tari daerah yang hampir sama dengan tari $l u l o^{7}$. Para pemain saling

Tarian lulo pada awalnya milik suku Tolaki, namun dalam perkembangannya telah meluas dan mulai di berkembang dan 
bergandengan tangan membentuk lingkaran sambil menyanyi seirama dengan langkah dalam tarian.

Keempat jenis kabhanti yang berkembang pada masyarakat Muna di atas, dalam tulisan ini hanya dianalisis teks-teks kabhanti kantola. Kabhanti kantola sebagai sebuah seni pertunjukan hingga saat masih fungsional dan kontekstual dalam perkembangan zaman. Bahkan, generasi tua masyarakat pemiliknya pun masih menjaga dan memeliharanya. Dalam tulisan ini hanya difokuskan pada analisis ungkapan-ungkapan (teks-teks) nyanyian rakyat kabhanti kantola yang fungsional dalam menyampaikan pesanpesan dakwah Islam.

\section{Dakwah Islam}

Aktivitas dakwah merupakan hal yang fundamental dalam menyebarkan nilai-nilai ajaran agama Islam. Bahkan tanpa dakwah, ajaran agama akan stagnan. Oleh karena itu, dalam menyampaikan nilai-nilai Islam diperlukan media untuk menyampaikannya. Di satu sisi dakwah dapat dilakukan secara modern, tapi pada sisi yang lain penyampaian materi dakwah secara tradisional masih menjadi pilihan yang tepat, khususnya pada masyarakat pedesaan yang belum tersentuh oleh kecanggihan teknologi informasi.

Dakwah menjadi cara untuk mengajak manusia ke jalan yang lurus sesuai dengan tatanan dan nilai-nilai ajaran Islam. Bahkan, melalui dakwah dapat mengubah dan membentuk individu dan kelompok masyarakat menuju ajaran dan nilai-nilai Islam. Dakwah Islam membentuk perubahan dan transformasi

dipertunjukkan hampir seluruh wilayah kabupaten/kota Provinsi Sulawesi Tenggara. Oleh karena, demikian kuat pengaruh dan meluasnya perkembangan hingga saat ini dikategorikan sebagai tari daerah Sulawesi Tenggara). Tarian ini para pemain saling bergandengan tangan membentuk lingkaran sambil menyanyi seirama dengan langkah dalam tarian yang diiringi dengan musik dangdut Orgen. sosial menuju tatanan masyarakat yang selaras dengan nilai-nilai Islam. ${ }^{8}$ Dakwah Islam yang berorientasi pada pesan-pesan keagamaan dan sosial-kemasyarakatan tentu menyentuh kesadaran individu atau kelompok untuk mengaktualisaikan nilai-nilai ajaran Islam di segala sendi kehidupannya. Bahkan, melalui dakwah dapat membebaskan individu dan masyarakat dari pengaruh eksternal (luar dirinya) menuju kontekstualisasi nilai-nilai Islam yang diyakininya.

Dakwah bermaksud menumbuhkembangkan pemahaman keagamaan dalam berbagai aspek ajarannya agar diaktualisasikan dalam bersikap, berpikir, dan bertindak. ${ }^{9}$ Dakwah juga sebagai sarana untuk mengajak manusia dengan cara bijaksana untuk menjalani kehidupan secara benar serta sesuai dengan perintah Tuhan agar mendapatkan kebahagiaan dan keselamatan baik di dunia maupun di akhirat. ${ }^{10}$

Dakwah sebagai sarana untuk menyampaikan ajaran Islam kepada sesama manusia memerlukan media efektif agar pesan dakwah yang disampaikan berdampak pada perubahan indvidu atau kelompok tanpa adanya unsur paksaan. Masyarakat Muna yang mayoritas penduduknya beragama Islam, memiliki cara tersendiri dalam menyebarluaskan nilai-nilai Islam, yakni dengan menyisipkan ajaran Islam dalam praktik kebudayaannya. Kebudayaan lokal dapat difungsikan sebagai sarana untuk menyebarkan nilai-nilai lokal dan ajaran Islam serta menciptakan keharmonisan hidup sesama manusia.

Argumentasi di atas, diperkuat pandangan yang mengatakan bahwa materi dakwah pada dasarnya dapat disampaikan dengan meng-

Irfan Hielmy. Dakwah Bil Himah, (Yogyakarta: Mitra Pustaka, 2002), h. 9-10.

M. Munir. Manajemen Dakwah, (Jakarta : Kencana Media Group, 2006), hal. 2.

10 Kafiudin dan Maman A. Jalil. Prinsip dan Strategi Dakwah, (Bandung: CV Pustaka Satia, 2001), h.3. 
gunakan media apa saja, melalui ceramah di atas mimbar, dakwah melalui nyanyian, bahkan di televisi pun sudah banyak menayangkan film-film yang berisikan pesan dakwah. ${ }^{11}$ Salah satu media yang dapat digunakan untuk berdakwah adalah budaya lokal yang dimiliki suatu komunitas/masyarakat. Masyarakat Muna sebagai satu masyarakat yang mendiami Pulau Muna Provinsi Sulawesi Tenggara memiliki beragam budaya lokal. Salah satu budaya lokal yang dimiliki adalah berupa nyanyian rakyat yang disebut kabhanti kantola.

Nyanyian rakyat ini dimanfaatkan oleh pemantun untuk menyelipkan pesan dakwah melalui teks-teks yang diciptakan pemantun. Dengan strategi komunikasi penyampaian pesan, pemain lain dan penonton yang mendengar kabhanti tersebut dapat mengetahui pesan dan makna yang terkandung di dalamnya. Melalui teks-teks kabhanti kantola makna dapat digali dan ditafsirkan untuk dipahami maknamakna yang terkandung dalam teks tersebut. Dengan kata lain, menghayati makna yang terkandung di dalam teks, dapat memberikan pemahaman yang mendalam terhadap nilainilai ajaran Islam.

Nyanyian rakyat kabhanti kantola yang dimiliki masyarakat Muna tidak hanya bermaksud untuk menghibur, tetapi juga memiliki bermaksud antara lain (1) mengkritik suatu perbuatan, sikap atau keadaan salah (keliru) menurut norma agama serta tata cara dan tata krama pergaulan; dengan demikian mengandung makna pendidikan moral dan akhlak agamis; dan (2) permohonan yang diungkapkan secara sastrawi. ${ }^{12} \mathrm{Hal}$ ini menunjukkan bahwa keberadaan kabhanti kantola dapat menjadi

\footnotetext{
11 Syarifah Farah. Analisis Isi Pesan Dakwah dalam Syar Lagu Gurp Musik Rock Pugatory Album 7:172), 2008. (Jakarta: Fakultas Dakwah dan Komunikasi UIN Sarif Hidayatullah, 2008), h. 12-13.

12 La Mokui. Kabhanti Wuna (Pantun Muna), (Raha: CV Astri Raha, 1994), h. 4
}

media dakwah yang berkaitan dengan nilainilai agamis (Islam).

Pemantun dalam hal ini, memegang peranan penting dalam memanfaatkan tradisi lokal (kabhanti kantola) dalam menyampaikan pesan dakwah. Dengan demikian, pemantun dalam menciptakan teks kabhanti kantola dapat dikatakan sebagai bentuk dan cara berdakwah berbasis tradisi lokal, yakni dengan memanfaatkan tradisi sebagai saluran untuk menyampaikan pesan dakwah kepada pemantun lain dan khalayak (penonton). Memanfaatkan tradisi lokal sebagai media dakwah, menjadikan dakwah 'selalu kontekstual'13, serta dekat dengan kebudayaan masyarakat.

Teks-teks kabhanti kantola yang diciptakan pemantun merupakan upaya kreatif dan inovatif yang dapat digali dan dimanfaatkan secara mendalam untuk menjadi media dakwah. Secara umum, makna teks-teks kabhanti kantola mengandung nilai-nilai yang berlandaskan pada nilai-nilai universal manusia. Dalam konteks ini, komunikasi memainkan peranan penting dalam transfer pengetahuan dakwah Islam kepada lawan mainnya (pematun lain) dan penonton. Proses penyampaian pesan dari pemantun (komunikator) kepada pemantun lainnya (komunikan) serta penonton merupakan proses komunikasi yang bersifat resiprokal. Pesan yang disampaikan sebagai kekuatan (energia) yang berpola itu, dapat mempengaruhi pikiran individu dan kelompok dalam mengambil keputusan dari kemungkinan pilihan-pilihan yang ada ${ }^{14}$. Dengan demikian, penyisipan pesan dakwah Islam dalam nyanyian rakyat kabhanti kantola pada masyarakat Muna

\footnotetext{
13 Istilah dakwah kontekstual merujuk pada tulisan Irawan Paputungan, dalam tulisannya berjudul "Transformasi Nilai-Nilai Seni dalam Dakwah, Studi terhadap Dialektika Dakwah dalam Kesusastraan' dalam Jurnal Aqlam, Volume 1, Nomor 2, Desember 2016, h. 6.

14 Wiryanta. Pengantar Ilmu Komunikasi, (Grasindo, Jakarta. 2006), h. 29.
} 
bertujuan untuk mempengaruhi pola pikir audiens untuk mengambil pilihan-pilhan yang baik terhadap pesan yang disampaikan.

Kabhanti kantola sebagai salah satu media komunikasi tradisonal merupakan "proses penyampaian pesan dari satu pihak ke pihak yang lain, dengan menggunakan media tradisional yang sudah lama digunakan di suatu tempat sebelum kebudayaan lokal tersentuh oleh teknologi modern". ${ }^{15}$ Penyampaian pesan dalam kabhanti kantola sebagai perwujudan proses komunikasi antara pemantun dengan pemantun lain dan penonton, di mana seseorang/kelompok (komunikator) menyampaikan isi pikiran dan perasaan kepada pihak lain (pemantun lain dan penonton). Pesan dari pemantun kabhanti kantola disampaikan kepada pemantun lain dan penonton, tidak terbatas pada informasi dakwah Islam, tetapi juga informasi lain yang dikembangkan berdasarkan pengetahuan pemantun.

Seperti dikemukakann di atas bahwa kabhanti kantola dalam fungsinya sebagai media komunikasi tradisional, oleh masyarakat pemiliknya digunakan sebagai media menghibur dan menyampaikan informasi sesuai kebutuhan yang berkaitan dengan kehidupan mereka, antara lain adalah pesan nilai-nilai agama (Islam). Hal ini sejalan dengan pandangan yang mengatakan bahwa "pengguna media diasumsikan khalayak yang aktif yang berusaha mencari sumber media yang bisa memenuhi kebutuhannya"16. Daya pikat lainnya, yang terdapat dalam pertunjukan kabhanti kantola adalah sifatnya yang akrab dan santai. Sebagai media hiburan dan transmisi pesan, kabhanti kantola tetap menjadi pilihan karena memberi-

15 Silvani dalam Hadirman. “Tradisi Katoba sebagai Media Komunikasi Tradisional dalam Masyarakat Muna”, dalam Jurnal Penelitian Komunikasi dan Opini Publik, Vol. 20. No. 1, Agustus 2016, (Manado: BPPKI Manado, 2016), h. 14

16 Jalaluddin Rahmat. Psikologi Komunikasi, (Bandung: PR Remaja Remaja Rosdakarya, 1991). kan stimulan, yakni kebutuhan untuk mendapatkan rangsangan demi keinginan menghindari kebosanan dalam hidup manusia. ${ }^{17}$

\section{Pesan Dakwah Islam dalam Teks-Teks Nyanyian Rakyat Kabhanti Kantola}

Pertunjukan tradisi lokal memiliki fungsi. ${ }^{18}$ Salah satu fungsi tersebut adalah media dakwah. Fungsi media dakwah dalam pertunjukan kabhanti kantola dalam tulisan ini berkaitan dengan transmisi teks nilai-nilai keagamaan berupa pengalaman, pikiran, dan perasaan (emosi) untuk menjadi manusia yang dapat menjalankan nilai-nilai agama Islam, melaksanakan perintah-Nya dan menjauhi laranganNya. Dalam konteks ini, kabhanti kantola tidak hanya sebagai suatu pertunjukan yang menghibur, ungkapan perasaan, juga menjadi wahana untuk menyebarkan pesan nilai-nilai Islam oleh pemantun maupun masyarakat yang menyaksikan pertunjukan tersebut.

Pesan sebagai salah satu unsur dalam proses komunikasi. ${ }^{19}$ Pesan adalah seperangkat lambang bermakna yang disampaikan komunikator. Lambang-lambang tersebut dapat berwujud antara lain bahasa isyarat, lukisan (gambar), dan sebagainya yang menterjemahkan pikiran dan perasaan komunikator kepada komunikan. ${ }^{20}$ Pembawa pesan (komunikator) dalam pertunjukan kabhanti kantola adalah pemantun, sedangkan komunikannya adalah pemantun lainnya dan penonton. Pesan yang disampaikan pemantun, dapat berupa ide, in-

S. Arifanto, (ed.). Dinamika Perkembangan, Pemanfaatan Teknologi Informasi dan Komunikasi serta Implikasinya di Masyarakat, (Jakarta: Kemkominfo RI dan Penerbit Media Bangsa Jakarta, 2013), h. 60.

18 Supanggah. “Konsep Garap: Salah Satu Model Pendekatan Kajian Musik Nusantara, dalam Pudentia (ed.) 2008. Metodologi Kajian Tradisi Lisan, (Jakarta: ATL, 2008), h. 296.

19 Jurnal RISALAH, FDK-UIN Suska Riau, vol. XXIV, Edisi 2, November 2013.

20 Onong S. Effendy. Ilmu Komunikasi Teori dan Paktik, (Bandung: Remaja Rosdakarya, 1994), h.18. 
formasi, nasihat, yang ditujukan untuk pemantun lainnya dan penonton yang menyaksikannya. Pesan yang disampaikan yang dianalisis dalam tulisan ini adalah pesan verbal berupa bahasa Muna sebagai medium penyampaian pesan dalam petunjukan kabhanti kantola. Pesan yang disampaikan dalam pertunjukan kabhanti kantola bersifat informatif. Artinya, pesan yang informatif yang dimaksudkan dalam tulisan ini adalah pemantun memberikan keterangan, pandangan, dan nasihat-nasihat dan kemudian komunikan dalam waktu yang sama mendapatkan pesan positif dari teks kabhanti kantola.

Masyarakat yang menyaksikan pertunjukan kabhanti kantola tersebut tertarik mendengar dan menyaksikannya tanpa ada paksaan. Pesan yang disampaikan mengandung makna dakwah Islam dan bagi yang mendengarnya tidak ada paksaan untuk mengikuti pesan yang didengarnya. Pemantun hanya menyampaikan saja nilai-nilai itu, melalui teks kabhanti yang diciptakannya. Tentu, pemantun berharap agar teks kabhanti yang diciptakannya dapat mempengaruhi pendengarnya, mengikuti atau hanya memperoleh pengalaman hidup melalui pesan kabhanti yang didengarnya.

Uraian di atas selaras dengan konsep dakwah yang berarti sebagai suatu kegiatan ajakan, yang berbentuk lisan dan tulisan, perilaku, dan sebagainya. Kegiatan dakwah tersebut dilakukan secara sadar dan terencana dalam usaha mempengaruhi orang lain (individu dan kelompok) agar memperoleh pengertian, kesadaran, pengalaman, serta penghayatan terhadap ajaran agama sebagai pesan yang disampaikan kepadanya tanpa unsur-unsur paksaan. ${ }^{21}$

Pesan dakwah tercemin dalam teks-teks kabhanti kantola yang disampaikan pemantun

21 M. Arifin. Psikologi Dakwah Suatu Pengantar, (Jakarta: Bumi Aksara, 1993), h. 17. kepada pemantun lain dan penonton. Pemantun menciptakan teks-teks kabhanti bernuansa dakwah ini mengharapkan agar bermanfaat bagi pemantun lain atau penonton yang mendengarkan dan menyaksikannya. Atas dasar itulah, mereka menciptakan teks-teks bahanti kantola yang mengandung pesan-pesan dakwah.

Teks-teks kabhanti kantola yang mencerminkan pesan dakwah Islam seperti contohcontoh berikut ini.

1) Noombahimo diu Sudah mulai tampak nomentegho (1) peril a k u y n g Nefaliando ngkamokulahi mengherankan (1) wawono (2) Yang dipantangkan orang Dadihano ntaidi hende tua dahulu (2) morangku (3) Jadi kitagenerasi muda (3) Bea notangka imani (4) Harus kuat iman (4) Sabhara giu somombano Semua pekerjaan yang itu (5)

Nabhali gara bari-barie Akan berubah semua ngkilate (6)

okamokula bhensangiahi (7)

Tabea dakofekirimo (8) keadaan (6)

Orang tua dan tokoh masyarakat (7)

Harus mulai memikirkan ini (8)

Teks Kabhanti kantola (1) di atas berisi gambaran perubahan zaman, yang mana di dalamnya terdapat perilaku yang tidak bersesuaian dengan nasihat orang tua. Teks kabhanti kantola ini, memberi satu kiat pada generasi muda untuk menguatkan iman pada Allah Swt., seperti tercermin pada teks Dadihanomo intaidi hende bughou/bea notangka imani 'Jadi kita generasi muda ini/harus kuat iman'. Teks ini, merupakan implementasi ajaran agama Islam untuk menguatkan iman. Iman adalah bentuk keyakinan secara totalitas pada kekuasaan Tuhan. Iman berarti pembenaran dalam hati, mengikrarkan dengan lisan dan mengamalkan dengan perbuatan. Iman pada keesaan Allah berarti memercayai bahwa hanya Allah yang memiliki sifat kesempurnaan dan terlepas dari 
sifat tercela atau kekurangan. ${ }^{22}$ Kata iman berarti kepercayaan atau mempercayai. Atau, ketetapan hati atau kepercayaan kepada Allah Swt. ${ }^{23}$ Objek-objek yang wajib diimani sesuai dengan ajaran Islam adalah (a) percaya kepada Allah Swt., percaya kepada malaikat, percaya kepada Kitab-kitab Allah, kepada Rasul-Nya, kepada hari kiamat, dan kepada qada dan qadar. Kewajiban beriman kepada enam unsur ini ditegaskan melalui ayat al-Quran dan hadishadis Nabi Muhammad saw.

Selain itu, teks kabhanti kantola (1) terdapat ungkapan yang bermakna bahwa membekali generasi muda menghadapi perkembangan zaman tidak hanya merupakan tanggungjawab individu, tetapi juga orang tua (anak) dan tokoh masyarakat. Orang tua dan tokoh masyarakat disarankan dalam teks kabhanti kantola di atas untuk membekali generasi muda dengan nilainilai agama dan budaya lokal agar generasi muda dapat menyesuaikan diri dengan perkembangan yang ada.

Perubahan zaman juga membutuhkan persiapan untuk menghadapinya. Oleh karena itu, orang tua dan tokoh masyarakat harus memikirkan cara-cara protektif agar generasi muda tidak menyimpang dari ajaran moralitas yang diwariskan generasi pendahulu mereka. Perubahan zaman harus diselaraskan dengan nilai-nilai agama dan budaya lokal tanpa harus terpengaruh dengan perkembangan zaman yang semakin menghawatirkan akan munculnya dekadensi moral pada generasi muda. Dalam hal ini, boleh saja zaman berubah, tetapi perilaku harus senantiasa berlandaskan pada nilai-nilai hidup yang berlandaskan ajaran

22 Suhardi Mukmin. Teori dan Aplikasi Semiotika. Edisi Revisi, (Palembang: Penerbit Unsri, 2008), h. 6

23 Ritonga, H.A. Rahman. Akidah Merakit Hubungan Manusia dengan Khaliknya melalui Pendidikan Akidah Anak Usia Dini, (Surabaya: Amelia, 2005), h. 54.

Islam dan pengetahuan yang telah diajarkan oleh orang tua dan tokoh masyarakat.

2) Dotunggu dhunia ini tabea

Menghuni dunia ini harusnsoda (1) Sapae nabhala nsoda (2) Djunia ntaweane dua (3)

lah bersabar' (1)

Jika tidak besar kesabaran

dunia rugilah juga (3)

Teks kabhanti kantola (2) di atas mengandung nasihat atau ajaran pentingnya bersabar dalam menjalani kehidupan di dunia ini. Dalam teks kabhanti kantola tersebut dikatakan bahwa jika manusia ingin hidup atau tinggal lama dan tenang di dunia ini, maka harus bersabar. Berbagai kesulitan dalam kehidupan tidak terelakan, sehingga kesabaran menjadi modal utama untuk menciptakan ketenangan dan menyelesaikan rintangan dan tantangan hidup. Manusia sebagai hamba Allah Swt. haruslah bersabar dalam menghadapi semua tantangan hidup ini. Bila cermati teks kabhanti kantola (2) tersebut sangat sesuai dengan ajaran agama Islam, yakni manusia yang tidak bersabar dalam menghadapi bebagai cobaan hidup maka dirinya tergolong orang yang merugi. Sebaliknya, bagi siapa yang selalu bersabar dalam menghadapi berbagai cobaan hidup ini maka dirinya termasuk orang yang beruntung.

3) Pudhi amenteanomo nsaidi marinantno ampa itu ne witeno

Wuna ini (1)

Kakoambahaku nagha kaasi indefie ini takala bhentatituno newuntano alo watu ne kabhalano alo (2)

Tamaka ampahi aitu anomarangkolipopomo pedamo ghole-gholeo (3) Aitu dadihanomo intadi Wuna ini (4) Atumola-tola ane ne Ompu Kakawasa (5) Hamadi sonighulumi mositi kanokasili (6)
Patut dibanggakan pemerintah sekarang di tanah Muna ini (1)

Saya mengatakan hal itu kasian di zaman dahulu kita jalan selalu tersandung di tengah jalan sana di tengah malam (2) Tetapi sekarang lihat sudah berkelap kelip seperti siang hari (3)

Jadi sekarang kita orang Muna ini (4)

Memohon kepada Tuhan Yang Mahaesa (6)

Apa saja yang kita tuju selalu berhasil (6) 
Teks kabhanti kantola (3) di atas memiliki makna berupa ungkapan rasa syukur masyarakat atas keberhasilan pemerintah dalam membangun daerah Muna. Secara tersurat teks kabhanti kantola di atas, di antaranya menggambarkan jalan-jalan telah baik dan lampu listrik telah menyala yang sebelumnya aliran listrik belum masuk di rumah-rumah warga. Dengan pembangunan yang dicapai pemerintah daerah seperti itu, pemantun mengajak pemain dan penonton mengucapkan rasa syukur kepada Allah Swt. agar apa yang direncanakan atau diusahakan pemerintah selalu berhasil. Hal ini direpresentasikan ungkapan Aitu dadihanomo intadi Wuna ini, atumola-tola ane ne Ompu Kakawasa, hamadi sonighulumi mositi nakohasili 'Jadi kita sekarang orang Muna ini, memohon kepada Allah Swt., apa saja yang kita tuju selalu berhasil'. Ungkapan ini merupakan bentuk penyerahan diri kepada Tuhan agar apapun yang diusahakan selalu berhasil dan dicapai sesuai yang direncanakan. Hal ini, merupakan bentuk rasa syukur atas karunia Allah Swt.

Rasa syukur erat kaitannya dengan nikmat. Nikmat yang telah diberikan oleh Allah kepada manusia amat banyak dan tidak ada yang mampu menandinginya. Sebagaimana Firman Allah dalam al-Quran, sebagai berikut.

Dan jika kamu menghitung nikmat Allah itu niscya kamu tidak mampu menghitungnya. Sesunggunya manusia itu amat zalim dan kafir (QS. 14:34).

Nikmat yang dianugerahkan Allah itu adalah hidup dan kehidupan. Hidup artinya keterpaduan antara jasmani dan rohani. Selama jasmani dan rohani masih bersenyawa, manusia disebut bernyawa atau hidup. Kehidupan artinya semua sumber daya alam ciptaan Allah yang dibutuhkan manusia untuk melangsungkan hidupnya. Dengan demikian, segala nikmat yang diberikan Allah Swt., sudah sepantasnya manusia menyukurinya.

4) Dadihanomo ntaidi ini hende bughou (1)

Jadi kita generasi muda ini Dakumakaro pologogho kamamungku (2) (1) Kita berlomba berbuat kebajikan (2)

Poghele-ghele weliwunto (3)

Malimu malegasino (4) Fehulai dadinto mada kaawu damanangkali ghumondoo kadadihanto (5)

Kotoginana kodo toangka (6)

Ne giu tapa mentela (7) Berlomba lomba di kampung kita (3) Biar kita disiplin (4) Kita pikirkan kehidupan nanti harus ulet melaksankan pekerjaan kita (5) Jangan mendekat jangan mengikut (6)

Pada pekerjaan yang tidak halal (7)

Ungkapan (4) di atas secara tekstual menyiratkan makna berupa nasihat pada generasi mudah untuk berlomba-lomba berbuat kebajikan, berbuat untuk kampung, belajar kedisiplinan, bekerja ulet, dan berusaha menjauhi pekerjaan yang tidak halal. Untuk itu diperlukan keselarasan nilai-nilai kultur lokal dan agama sebagai pedoman dalam memilah dan memilih pekerjaan.

Secara mendalam pesan kabhanti kantola (4) di atas mengajarkan manusia untuk menggunakan nilai-nilai agama sebagai sandaran untuk mencari dan memilih pekerjaan yang halal. Hal ini mengindikasikan bahwa tata perilaku, termasuk perilaku manusia dalam memilik pekerjaan yang baik (halal) tidak hanya menjadi pembeda dan pewujud kehidupan manusia, tetapi perilaku berbudaya (termasuk beragama) itu harus memiliki nilai lebih bagi kehidupan itu sendiri dan selaras dengan nilai-nilai budaya dan agama yang diyakini. ${ }^{24}$

24 Bagus, I.G.N. "Keresahan dan Gejolak Sepuluh Tahun Terakhir di Bali. Beberapa Catatan tentang Perubahan Sosial di Era Globalisasi", dalam Cambert-Loir dan Ambary (ed.), Panggung Sejarah Persembahan Kepada Prof. Dr. Denys Lombar, (Jakarta: Yayasan Obor Indonesia, 1997), h. 50. 
Salah satu kebutuhan manusia adalah mendapatkan harta yang cukup untuk memenuhi kebutuhan hidup diri dan keluarganya. Akan tetapi, harta yang dibutuhkan seyogianya membawa keselamatan bagi pemiliknya. Oleh sebab itu, harta atau barang harus jelas batasannya, sebagai miliki pribadi, atau milik orang lain. Bila itu bukan miliki kita, maka dapat pastikan bukan hak kita. Demikian pula, milik orang lain adalah hal orang tersebut. Tidak diperbolehkan untuk mengambil hak-hak orang lain. Bila mengambil hak atau barang orang lain, maka dikategorikan sebagai barang haram. Bagi pelakunya adalah dikategorikan sebagai perbuatan yang mendatangkan dosa. Kehidupan dewasa ini nyaris sudah membedakan barang haram dan halal. Hak-hak menjadi milik kita sedangkan hal orang lain perlu kita jauhi. Pesan kabhanti kantola (4) di atas berkaitan dengan nasihat untuk menjauhi pekerjaan yang halal bukan sebaliknya.

Pada ungkapan kabhanti kantola (4) di atas juga tampak adanya ketahanan diri generasi muda dalam hal mencari pekerjaan. Generasi muda tidak boleh mendekati dan mengikuti perkerjaan yang tidak baik (melanggar hukum agama). Hal itu tampak pada ungkapan dadihanomo intaidi hende bughou, konotoginana kodotoangka ne giu pata mentela 'Jadi kita generasi muda ini, jangan mendekat dan jangan mengikut pada pekerjaan yang tidak halal'. Ketahanan diri terdapat pada ungkapan konotoginana kodotoangka 'jangan mendekat dan jangan mengikut' dan negiu pata mentela 'pekerjaan yang tidak halal'. Ungkapan tersebut bermakna ketahanan diri, yakni agar seseorang tidak mendekati dan mengikuti pekerjaan yang tidak baik. Dengan ungkapan seperti ini, kabhanti kantola berfungsi sebagai media membentuk karakter generasi muda.
5) Aitu maka bhelahi tabea moko tabea sangia kosibharindo (1)

Insaidi tapongkarame alo nsealono itu (2) Aitu dadihanomo daseneaneatiha ne Ompu Kakawasa (3)

Teks kabhanti kantola (5) di atas tampak pemantun mengungkapkan bahwa mereka akan memulai pementasan dan meminta izin kepada semua yang hadir. Ungkapan tabea mokotabea 'permisi' sebagai bentuk permohonan pamit/izin. Kata tabea 'permisi' merupakan sesuatu yang wajib dipahami oleh semua masyarakat Muna. Kata ini dalam bentuk aktivitas yang lain, dilakukan pula pada saat lewat di hadapan orang tua atau orang yang lebih tua harus mengucapkan tabea 'permisi'. Siapa saja yang tidak mengucapkan kata ini apabila lewat di hadapan orang yang lebih tua, terutama pada saat mereka duduk dalam suatu upacara, akan dianggap tidak memahami adat Muna. Alasan itu pulalah menyebabkan pemantun kabhanti kantola mengucapkan kata tersebut. Mengucapkan tabea 'permisi' sebagai implementasi pesan moral yang diajarkan orang tua dan generasi pendahulunya.

Teks kabhanti kantola (5) di atas bermakna pula pemantun mengajak para pemantun lainnya, penonton, dan masyarakat yang menyaksikan pertunjukan untuk mengucapkan permohonan kepada Allah Swt. atas selesainya pertunjukan kabhanti kantola. Pesan yang terkandung dalam ungkapan tersebut adalah dalam mengakhiri pertunjukan kabhanti kantola, para pemantun dan penonton harus berniat kepada terlebih dahulu kepada Allah Swt. Hal ini sesuai dengan pemahaman agama Islam bahwa dalam melakukan aktivitas apapun di dunia ini harus diawali dan diakhiri dengan berdoa pada Allah Swt. Ajakan berdoa sebagai 
bentuk membangun hubungan dengan Tuhan kabhanti (5) direpresentasikan ungkapan dadihanomo aitu dasenea-neatiha jadi sekarang kita berniat' sedangkan tujuan doa disampaikan ditujukan pada Allah yang direpresentasikan ungkapan ne Ompu Kakawasa 'pada Allah Swt.'.

Pemantun menegaskan bahwa mereka hanya berpesta semalam suntuk, yang ditandai oleh ungkapan insaidi tapongkarame alo nsealono itu 'kami hanya berpesta malam semalam suntuk ini'. Hal ini menandakan bahwa mereka terhimpun dalam suatu acara, yakni pertunjukan kabhanti kantola. Ungkapan yang menunjukkan solidaritas seperti tampak pada ungkapan aitu dadihanomo dansinia-niatiha ne Ompu Kakawawa 'Jadi sekarang kita berniat pada Allah Swt.. Ungkapan tersebut menunjukkan komunikasi langsung antara sesama pemain, pemain, dan penonton. Pemakaian bentuk terikat da- 'kita' pada kata dansinianiatiha 'kita niat bersama' menunjukkan makna himpunan, kesatuan, dan solidaritas dalam kehidupan sosial. Ungkapan tersebut menggambarkan solidaritas untuk memohon secara bersama-sama berupa keselamatan kepada Allah Swt. demi kelancaran dan keberhasilan pertunjukan nyanyian rakyat kabhanti kantola.
6) Aitu dosipilimo dapogurumo daano (1) Dapofosi-fosibhala dapoangka-angkatau (2) Konae ntigho norongga nepogurughoo ini (3) Salapasino aitu daesalomo rahamati ne Ompuno Kakawasa (4)
Pilihan sama belajar sungguh (1)

Saling menghargai seia sekata (2)

Agar utuh pelajaran kita (3) Kemudian kita memohon rahmat pada Tuhan Yang Maha Esa (4)
Teks kabhanti kantola (6) memiliki makna pentingnya belajar menghargai sesama manusia. Manusia sudah sepantasnya menghargai manusia lainnya. Karena seseorang yang telah belajar suatu ilmu pengetahuan jika belum menghargai orang lain belum dianggap mema- hami secara benar ilmu yang telah dipelajarinya. Pesan yang berkaitan dengan pentingnya belajar menghargai orang lain tampak pada ungkapan dapofosi-fosibhala dapoangkaangkatau, konae ntigho norongga nepogurughoo ono 'saling menghargai seia sekata, agar utuh pelajaran kita'.

Setelah mengamalkan ajaran pada ungkapan di atas, langkah selanjutnya adalah menyerahkan diri secara totalitas kepada Allah Swt. agar ilmu yang dipahami tetap utuh dan kebiasaan dalam menghargai orang lain tetap terjaga dalam diri seseorang. Penyerahan diri secara totalitas kepada Allah Swt. direpresentasikan ungkapan salapasino aitu daesalomo rahamati ne Ompuno Kakawasa 'kemudian kita memohon rahmat pada Allah Swt.'. Ungkapan ini menunjukkan kedekatan manusia dengan Tuhan. Apapun yang telah diyakini dan dipedomaninya dalam kehidupan ini selalu memohon kepada Allah Swt. untuk mendapatkan rahmatNya. Maksudnya adalah rahmat Allah Swt. untuk selalu dijaga dan dibimbing ke hal yang baik dalam menjalani kehidupan manusia sehari-hari.

Teks kabhanti kantola yang menggambarkan relasi sosial baik, yakni menjauhi perbedaan dan bersalah paham, serta perlunya mementingkan kebersamaan, tampak pula pada ungkapan berikut ini. 
$7 \quad$ Ane pedamo anagha patudhu solalomu (1) Welongkarame, gara dosikalentumo sintuumu bheinsaidi (2) Dadihanomo bhelahi mbasi-mbasitiehiku (3) Ne witeno Wuna ini, damekakodoho posimbi (4)

Mosibhala kaseise, woraeworaetua sada seise (5) Fekiri intaidi Wuna ini, hamadi sonewiseki mositi nakohasili (6)

Rampano peda aini, kasemie-miehano nobansie kaposimbi (7) Tabea o kaseise maka nemasighoono (8) Wawono dhunia ini (9) Fetingke nagha kabhala welo ngkarame ini (10) Aitu dadihanomo intaidi Wuna ini (11)

Dameki-mekiriemo wula somombano ini (12) Raafulu tolu alo tolu alo kabhasanomo maludhu kapoi-pointaraha lima (13) netaagho namisino imamuno Wuna ini (14)
Sadhakano poliwu

Kalau seperti ini tujuan hati (1)

Dalam keramaian, padahal sudah satu tujuan dengan kami (2) Oleh karena itu, kalian saudara-saudaraku (3) Di tanah Muna ini, mari kita jauhkan perbedaaanperbedaan (4)

Lebih mementingkan kebersamaan, orang Muna jika bersatu (5) Pikirkan kita orang Muna apalagi yang kita hadapi ini mesti ada hasilnya (6) Karena seperti ini, Tuhan tidak suka salah paham (7)

Akan tetapi yang Dia sukai kecuali kebersamaan (8) Di atas dunia ini (9) Dengarkan petinggi di tengah keramaian ini (10) Jadi, sekarang kita ini sebagai orang Muna (11) Kita mulai pikirkan juga bulan yang akan muncul nanti (12)

Dua puluh tiga malam perayaan Maulid, berpegangan tangan (13) Sedekahnya daerah agar perasaan pemimpin Muna berbahagia (14)

Ungkapan (7) di atas menunjukkan bahwa pemantun memberikan gagasannya tentang perilaku yang baik sebagai masyarakat Muna. Ungkapan ne witeno Wuna ini 'di tanah Muna ini' sebagai latar tempat dan ungkapan damekakodoho posimbi 'kita jauhkan salah paham' memuat gagasan berupa imbauan menjauhkan bersalah paham dalam kehidupan bermasyarakat di Muna. Ungkapan mosibhala kaseise 'lebih mementingkan kebersamaan' memuat gagasan bahwa dalam hidup ini rasa kebersamaan perlu diposisikan sebagai hal yang utama, karena mementingkan kebersamaan hidup ini akan serasa indah, nyaman, dan damai. Ungkapan mosibhala kaseise 'lebih mementingkan kebersamaan' merupakan pola kehidupan mementingkan kebersamaan atau hidup yang penuh solidaritas. Solidaritas akan terbentuk apabila dalam masyarakat tidak ada keretakan sosial dan selalu tolong-menolong antara satu dan yang lainnya.

Teks kabhanti kantola (7) di atas menunjukkan pula bahwa kalau bersama apapun yan dilakukan selalu berhasil, seperti yang direpresentasikan ungkapan Sadaseise hamadi soniwiseki mositi nakohasili 'Jika bersama/ bersatu apa yang dihadapi akan selalu berhasil'. Hal ini menggambarkan bahwa hidup yang penuh kebersamaan segala sesuatu yang dihadapi akan bisa diselesaikan secara bersamasama dengan penuh kekeluargaan. Artinya, melalui gotong-royong apapun yang dikerjakan dapat berhasil dengan baik, pekerjaan yang berat menjadi ringan.

Salah paham sesama manusia (posimbi) tidak hanya merugikan manusia yang bersalah paham, tetapi juga mendapatkan murka dari Allah Swt. Allah Swt. sebagai pencipta manusia tidak menyukai sifat ini, Dia lebih menyukai kaseise 'kebersamaan', seperti yang diamanatkan pada ungkapan kasemie-miehano nobansie posimbi, tabeano kaseise 'Allah Swt. tidak menyukai salah paham, akan tetapi yang Dia sukai kecuali kebersamaan'. Ungkapan kasemiemiehano 'Allah Swt.' dalam ungkapan kabhanti kantola di atas mengindikasikan pula manifestasi keyakinan dan pandangan hidup masyarakat Muna bahwa apa pun aktivitas manusia selalu dalam pantauan dan penilaian Allah Swt.

Teks kabhanti kantola (7) di atas mengamanatkan pula untuk mempersiapkan diri terhadap segala kemungkinan yang terjadi pada masa yang akan datang, seperti ungkapan dameki-mekiriemo wula somombano ini 'kita mulai pikirkan juga bulan (peristiwa/kejadian) 
yang akan muncul nanti'. Ungkapan ini bermakna bahwa orang Muna harus tanggap darurat atau mempersiapkan diri dalam meng hadapi segala kemungkinan yang ada pada masa yang akan datang. Ungkapan damekimemikiriemo 'kita mulai pikirkan' bermakna berpikir di awal atau merespons dari awal segala hal yang berkaitan dengan kehidupan dan masa depan mereka sebagai orang Muna yang memiliki tanah dan tujuan hidup, sebagaimana yang dicita-citakan.
8) Ane nsaidi tatolimpapa (1)

Taesalo ane maafu (2) Intaidi sitiehiku wuntano ngkarame ini (3) Ane bhekaghosa bheradhaki ne Ompu Kakawasa (4) Dapogawa-ghawa tora karame ne wise itu (5)
Jika kami ada kata-kata yang salah (1)

Kami memohon maaf (2) Kepada semua saudaraku di tengah acara ini (3) Jika ada kekuatan dan rejeki dari Tuhan Yang Maha Esa (4) Kita akan bertemu lagi pada acara yang akan datang (5)
Teks kabhanti kantola (8) di atas berisi permohonan maaf para pemantun kabhanti kantola kepada pemantun lain dan penonton terhadap ungkapan kabhanti kantola yang telah dilansirnya dalam pertunjukan. Pentingnya permohonaan maaf terlebih dahulu sebelum berbicara atau berkata-kata adalah bagian dari etika dalam berbicara dan juga selaras dengan ajaran agama Islam. Kemudian pada teks yang lain terdapat ungkapan permohonan kesehatan, kekuatan, rejeki kepada Allah Swt. Seperti pada ungkapan ane bhekaghosa bheradhaki ne Ompu Kakawasa 'Jika ada kekuatan dan rejeki dari Allah Swt.'. Ungkapan ini merupakan bentuk doa yang dipanjatkan kepada Allah Swt. untuk mendapatkan pertolongan-Nya. Jika manusia dianugerahi sehat fisik dan jiwa, kekuatan pikiran dan fisik, akan lebih mudah mengerjakan sesuatu mendapatkan untuk mendapatkan rejeki. Bila manusia diberikan kesehatan lahir dan batin, tentunya akan lebih mudah untuk bertemu lagi pada pertunjukan kabhanti kantola pada kesempatan yang lain, seperti digambarkan ungkapan dapogawa-ghawa tora karame ne wise itu 'kita akan bertemu lagi pada acara yang akan datang'.

\section{PENUTUP}

Masyarakat Muna memiliki budaya lokal yang dapat dijadikan sebagai media dakwah dalam mentransmisikan nilai-nilai ajaran agama Islam. Budaya lokal tersebut adalah nyanyian rakyat kabhanti kantola. Nyayian rakyat kabhanti kantola selain dipertunjukan untuk seni hiburan, juga pemantun mampu menyisipkan pesan-pesan dakwah Islam dalam teks-teks kabhanti kantola yang diciptakannya. Pesan-pesan dakwah Islam yang disampaikan pemantun kabhanti kantola berkaitan dengan nilai-nilai hidup universal. Pesan-pesan dakwah Islam tersebut, antara lain berupa (1) pesan menguatkan keimanan kepada Allah, (2) pesan mensyukuri nikmat Allah, (3) pesan menjauhi barang haram, (4) pesan menghargai sesama manusia, (5) pesan perlunya memohon maaf.

Hadirnya pesan-pesan dakwah Islam yang tercermin dalam teks-teks kabhanti kantola menunjukkan bahwa budaya lokal ini masih tetap fungsional bagi masyarakat pendukungnya. Meskipun demikian, bila para ahli warisnya (generasi muda) tidak berminat untuk mempelajari nyanyian ini, pada masa-masa mendatang dikhawatirkan akan mengalami kepunahan. Oleh karena itu, upaya pawarisan dari generasi tua kepada generasi muda mutlak diperlukan agar budaya lokal ini dapat tetap bertahan dari ancaman kepunahannya. 


\section{DAFTAR PUSTAKA}

Anceaux, J.C. The Wolio Language: Outline of Grammatical Deskription and Texts. Holand: Foris Publications, 1988.

Arifin, M. Psikologi Dakwah Suatu Pengantar. Jakarta Bumi Aksara, 1993, h. 17.

Asrif. "Sastra Kabanti: Pengertian, Jenis, dan Fungsi" dalam Kandai Jurnal Bahasa dan Sastra Vol. 6, No. 2 November 2010. Kendari: Kantor Bahasa Provinsi Sulawesi Tenggara, 2010.

Bagus, I.G.N. "Keresahan dan Gejolak Sepuluh Tahun Terakhir di Bali. Beberapa Catatan tentang Perubahan Sosial di Era Globalisasi", dalam Cambert-Loir dan Ambary (ed.), Panggung Sejarah Persembagan Kepada Prof. Dr. Denys Lombar. Jakarta: Yayasan Obor Indonesia, 1997, h. 5.

Farah, Syarifah. Analisis Isi Pesan Dakwah dalam Syar Lagu Gurp Musik Rock Pugatory Album 7:172), 2008. Jakarta: Fakultas Dakwah dan Komunikasi UIN Sarif Hidayatullah. h. 1213

Hadirman. "Tradisi Katoba sebagai Media Komunikasi Tradisional dalam Masyarakat Muna", dalam Jurnal Penelitian Komunikasi dan Opini Publik, Vol. 20. No. 1, Agustus 2016. Manado: BPPKI Manado, 2016 h. 14. Hielmy, Irfan. Dakwah Bil Himah. Yogyakarta: Mitra Pustaka, 2002, h. 9-10.

Jalil, Maman A. dan Kafiudin. Prinsip dan Strategi Dakwah. Bandung: CV Pustaka Satia, 2001, h.3

La Mokui. Kabhanti Wuna (Pantun Muna), Raha: CV Astri Raha, 1994, h. 4

La Niampe. 1998. "Kabhanti Bula Malino: Kajian Filologi Sastra Wolio Klasik”. Tesis. Bandung: Program Pascasarjana Universitas Padjadjaran.
Mukmin, Suhardi. Teori dan Aplikasi Semiotika.

Edis Revisi. Palembang: Penerbit Unsri, 2008, h. 6

Mulyana, Deddy. Ilmu Komunikasi Suatu Pengantar. Bandung: Remaja Rosdakarya, 2009, h. 24.

Munir, M. Manajemen Dakwah. (Jakarta : Kencana Media Group, 2006), hal. 2.

Nasution. H. Pandapotan, 2005. Adat Budaya Mandailing dalam Tantangan Zaman. Medan: Forkala.

Paputungan, Irawan. “Transformasi Nilai-Nilai Seni dalam Dakwah, Studi terhadap Dialektika Dakwah dalam Kesusastraan' dalam Jurnal Aqlam, Volume 1, Nomor 2, Desember 2016. Manado: IAIN Manado, h. 6.

Rahmat, Jalaluddin. Psikologi Komunikasi. Bandung: PR Remaja Remaja Rosdakarya, 1991.

Ritonga, H.A. Rahman. Akidah Merakit Hubungan Manusia dengan Khaliknya melalui Pendidikan Akidah Anak Usia Dini. Surabaya: Amelia, 2005, h. 54.

S. Arifanto, (ed.). Dinamika Perkembangan, Pemanfaatan Teknologi Informasi dan Komunikasi serta Implikasinya di Masyarakat. Jakarta: Kemkominfo RI dan Penerbit Media Bangsa Jakarta, 2013, h. 60.

Supanggah. "Konsep Garap: Salah Satu Model Pendekatan Kajian Musik Nusantara, dalam Pudentia (ed.) Metodologi Kajian Tradisi Lisan. Jakarta: ATL, 2008, h. 296.

Wiryanta. Pengantar Ilmu Komunikasi. Jakarta: Grasindo, 2006, hlm. 29 
JURNAL AQLAM -- Journal of Islam and Plurality-- Volume 2, Nomor 2, Desember 2017 